"Determinants of price reversal in high-frequency trading: empirical evidence from Indonesia"

\begin{tabular}{|c|c|}
\hline AUTHORS & Perdana Wahyu Santosa id https://orcid.org/0000-0002-0221-3910 \\
\hline ARTICLE INFO & $\begin{array}{l}\text { Perdana Wahyu Santosa (2020). Determinants of price reversal in high- } \\
\text { frequency trading: empirical evidence from Indonesia. Investment Management } \\
\text { and Financial Innovations, 17(1),175-187. doi:10.21511/imfi.17(1).2020.16 }\end{array}$ \\
\hline DOI & http://dx.doi.org/10.21511/imfi.17(1).2020.16 \\
\hline RELEASED ON & Thursday, 19 March 2020 \\
\hline RECEIVED ON & Wednesday, 27 November 2019 \\
\hline \multirow[t]{2}{*}{ ACCEPTED ON } & Thursday, 20 February 2020 \\
\hline & $(\mathrm{cc}) \mathbf{E Y}$ \\
\hline LICENSE & $\begin{array}{l}\text { This work is licensed under a Creative Commons Attribution } 4.0 \text { International } \\
\text { License }\end{array}$ \\
\hline JOURNAL & "Investment Management and Financial Innovations" \\
\hline ISSN PRINT & $1810-4967$ \\
\hline ISSN ONLINE & $1812-9358$ \\
\hline PUBLISHER & LLC "Consulting Publishing Company "Business Perspectives" \\
\hline FOUNDER & LLC "Consulting Publishing Company "Business Perspectives" \\
\hline & 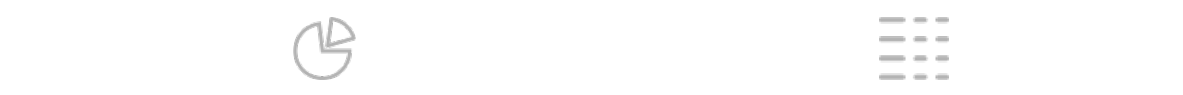 \\
\hline NUMBER OF REFERENCES & NUMBER OF FIGURES \\
\hline 42 & 0 \\
\hline
\end{tabular}

(C) The author(s) 2023. This publication is an open access article. 


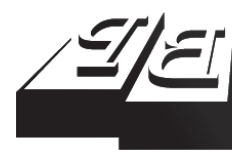

BUSINESS PERSPECTIVES

(O)

LLC "CPC "Business Perspectives" Hryhorii Skovoroda lane, 10 Sumy, 40022, Ukraine www.businessperspectives.org

Received on: $27^{\text {th }}$ of November, 2019 Accepted on: $20^{\text {th }}$ of February, 2020 Published on: $19^{\text {th }}$ of March, 2020

(c) Perdana Wahyu Santosa, 2020

Perdana Wahyu Santosa, Research coordinator, Faculty of Economics and Business, YARSI University, Indonesia.

This is an Open Access article, distributed under the terms of the Creative Commons Attribution 4.0 International license, which permits unrestricted re-use, distribution, and reproduction in any medium, provided the original work is properly cited.

Conflict of interest statement: Author(s) reported no conflict of interest

Perdana Wahyu Santosa (Indonesia)

\title{
DETERMINANTS OF PRICE REVERSAL IN HIGH-FREQUENCY TRADING: EMPIRICAL EVIDENCE FROM INDONESIA
}

\begin{abstract}
This article analyzes whether the factors of the mechanism of high-frequency trading (HFT) or intraday trading affect the process of price reversal and continuation. The price reversal phenomenon is gaining importance rapidly due to the increasingly in tensive use of IT/Fintech-based trading automation facilities on the Indonesia Stock Exchange. However, one knows little about how their trading affects volatility and liquidity pressures that cause price reversals. A new research approach uses the factors of market microstructure mechanism based on high-frequency data (HFD-intraday). The research method uses purposive random sampling, which classified price fractions into three groups, specifically low price, medium price, and high price, which are analyzed by logistic panel regression. The research variables used include price reversal (dependent), stock return, trading volume, transaction frequency, volume/ frequency (V/F) proxy, volatility, and liquidity. According to low price model research findings, all variables show a significant effect on price reversal; for medium price model, all variables except liquidity show a significant effect on price reversal; and for high price model, all variables have a significant effect on price reversal, except trading volume and volatility. In conclusion, low price shares tend to have higher price reversal probability compared to continuity because they tend to be liquid, low institutional ownership, and minimal reporting/analysis and are controlled by HFTs (uninformed traders). Some variables are not significant because of the bounce effect around the bid-ask spread.
\end{abstract}

\section{Keywords}

JEL Classification

\section{INTRODUCTION}

Information is the critical role played in the price reversal in the price forming process is well documented. However, the research gap in this area still exists, especially in an emerging market because of the differences in market microstructure and a "small" trading volume per day. One of the critical determinants of price reversal is the behavior of informed traders who prefer using large trades based on the private information they have. The reason for using large trading volume with high liquidity shares is to minimize transaction costs and maximize the trading gained from their informed high-frequency trading activity in the equity market, like Indonesia stock exchange. In contrast with this study, most existing research on how asymmetric information is incorporated into stock price reversal through overreaction in the market could be short-lived.

Dyl (2017) stated that several recent surveys on price reversal in capital market studies consistently show that the market microstructure becomes increasingly interdependent globally. Besides, overreaction studies are conducted when market momentum or time is crucial be- 
cause those market anomalies were found to be related to how fast the investor responses to dramatic or substantial information (Santosa \& Santoso, 2019). The hypothesis of price reversal argues that over-informed investors now encourage over-trading that causes initial price shocks and price reversals (Santosa \& Hosen, 2011). On the other hand, if investors are slow to respond to relevant information entering the market (underreaction), then what happens is price continuation (Savor, 2012).

Moreover, the current trading frequency is higher due to the use of IT/Financial technology (Fintech) and automated trading facilities globally, including the Indonesia Stock Exchange. Most of the trading on the equity market today is automatic, and most of this electronic trading comes from short-term investors known as high-frequency traders (HFTs). Goldman Sachs reported that Wall Street analysts discussed many of these HFT issues, in addition to the human decision that began to be replaced by machines in equity trading (Kimani, 2018). JP Morgan estimates that human-based equity trading is only about 10 percent of daily transaction volume, while 90 percent is controlled by HFT-based quantitative trading, algorithmic trading, and arbitration statistics with sophisticated models, and computer modeling to automate the equity trading process (Kimani, 2018).

Based on descriptive observations on the Indonesia Stock Exchange, equities of all price fractions (tick size) under normal conditions indicate a potential price reversal probability ranging from 18.7 to $24.3 \%$ with an average of $20.6 \%$ during 15 minutes. This general pattern shows that the possible price reversal is significant enough to create stock trading risks, especially in the short term, while the frequency of price reversals in one trading day ranges between 8 and 16 times, both major and minor reversals (Santosa \& Hosen, 2011).

This research provides novelty because it used the market microstructure theory approach based on high-frequency data (HFD) and analyzed through logistic regression so that it can discuss the probability of price reversal. So far, in Indonesia, the price reversal process has only been detected by technical analysis, and that is no longer accurate. Thus, this study tries to analyze the factors that cause the probability of price reversal and detect signals or timings to decide when to sell and buy on HFT activities on the Indonesia Stock Exchange. This study intends to fill previous related research and, therefore, to contribute to the existing literature.

\section{LITERATURE REVIEW}

On the Indonesia Stock Exchange, price reversal is more dominant than price continuation, both in the opening and closing markets. In the US (NYSE) and Japan (TSE), for example, the situation is different, where price continuation is stronger than price reversal, especially in the closing market (Santosa \& Hosen, 2011). This empirical fact is due to the trading rules on the Indonesia Stock Exchange using the continuous auction method, without the role of market makers and specialists being replaced by HFT, throughout the trading day. With the HFT replaced market maker role, the liquidity and open-to-open price volatility tends to be higher than the close-to-close liquidity and volatility (Santosa \& Hosen, 2011). Besides, the semi-strong form of market efficiency on the
Indonesia Stock Exchange and market microstructure also influences the high probability of stock prices reversal (Santosa \& Santoso, 2019).

The dynamics of the price movements of equity securities or commodities in the market shows the functioning of asset trading mechanisms efficiently and effectively in price discovery (Xu \& Rao, 2018). However, overreaction increases the probability of price reversal, so it deserves special attention in various earlier scientific articles (Cheng, Hameed, Subrahmanyam, \& Titman, 2014). The impetus to study this problem is how short-term predictability of the pattern of stock returns overreact after relatively significant price changes. Some previous literature describes the pattern of pricing after big price changes, including liquidity, overreaction, and underreaction hypothesis (Dyl, Yuksel, \& Zaynutdinova, 2019; So \& Wang, 2014). 
Liquidity provision-based describes the price reversal and continuation framework as compensation (fee) for liquidity providers, which have maintained a balance of buy and sell orders that take place in the short-term trading (Cheng, Hameed, Subrahmanyam, \& Titman, 2017).

Unfortunately, one knows little about how the HFT trading affects volatility and liquidity pressures that cause price reversals as a consequence of price corrections for any overreaction. So far, HFT acts only as a "market maker." They are more likely to be liquidity providers in the market and liquidity is a critical feature as new leverage in the modern financial market (Biais, Foucault, \& Moinas, 2015). Besides, Hirschey (2013) stated that HFT also look for transaction data and order flow to get hints (clues-signals) about which direction the price will move next, and when they trade based on this information, they can compete with traditional long-term investors (funds/asset managers) thereby increasing the transaction costs of these investors (Breckenfelder, 2013)

Semi-strong equity markets efficiency forms like the Indonesia Stock Exchange often experience panic buying and panic selling that makes overreaction, which is followed by price corrections, shortly. This condition is called noise trading caused by the arrival of information/news to the market, which is overreacted and based on the limited (weak) analysis (Tetlock, 2011). Excessive behavior occurs when the market receives good news or bad news, and bad news tend to be more reactive than good news (Wu \& Choudhry, 2018). This opinion contributes that in emerging markets such as Indonesia Stock Exchange, there is a potential for price reversal probability that is greater than the emerging market (Choudhry \& Wu, 2015). They also state that the price reversal process is also influenced by the effect of asymmetric momentum continuously (overtime), which causes up and down market indices to be more intense and systemic.

Important factors that determine the magnitude of price reversals and continuity after a price shock are liquidity and volatility. There are similarities and differences in stock characteristics that affect the magnitude of price reversal and continuation, confirm liquidity and underreac- tion and overreaction hypothesis (Kudryavtsev, 2019). First, stock liquidity is a significant determinant of the price reversal and continuation of asset prices (Dyl et al., 2019). To be exact a smaller company shares with lower institutional ownership were found to experience higher price reversals following the price shocks. Second, consistent with the arguments of Cheng et al. (2017) that changes in initial trade prices reflect private information and positively influence the level of overreaction, the push of price reversals was found to be powerful for equities with large price shocks and significant cumulative returns before event day.

Conversely, the magnitude of price continuation is relatively smaller when the initial price change is more extreme than the average return. Besides, stocks with abnormal trading volumes have the potential to experience higher reversals as well. This finding also supports the explanation of price reversals based on temporary liquidity pressures (Conrad, Wahal, \& Xiang, 2015). Dyl et al. (2019) show that an increase in transaction volume can indicate price pressures that lead to subsequent price reversals (Chordia, Roll, \& Subrahmanyam, 2011). Thus, the opinion is consistent across different periods/horizons and their continuity, including one, three, and ten days after price shocks on the day of the fundamental-dramatic event (Angel \& McCabe, 2013).

Theoretically, stock price movements in the capital market tried to reflect almost all information entering the market following the form of efficiency, both past, public, and private information (Bloomfield, O’Hara, \& Saar, 2009). Nevertheless, in reality, stock prices often experience overvalued or undervalued due to various factors, especially uncertainty in the form of the value of market fluctuations (Santosa \& Hosen, 2011). These conditions make the price of the asset not represent its intrinsic value, or in other words, the share price always has a mispricing position where there is always a difference between the intrinsic value and the market price (Savor, 2012). The equity price that underwent the mispricing process continued to search for its intrinsic value through repeated price corrections resulting in price reversals. The price correction process repeatedly occurs, creating price volatility and systemic and risky liquid- 
ity pressures. This general phenomenon forms a consistent pattern to create a gap or mismatch between theoretical valuations and empirical facts (Cheng et al., 2017; Santosa, 2011).

Consistent with the hypothesis of price reversal, issuers with price shocks on the day of an event tend to create price reversals. Also, the study found that a smaller cumulative abnormal return with a higher trading volume before the event were positively correlated with the price reversal probability after a day price shock (Benos \& Sagade, 2012). The explanation of underreaction that the return continuation shows more likely to create after the issuer's earnings announcement is consistent. Thus, the findings of previous studies provide further support and state that company-specific financial information has a significant influence on price continuity (Conrad, Wahal, \& Xiang, 2015). Overall, the conclusion shows that the market underreacts to information about the company's financial statements and overreacts to price movements of non-information-based (fad trading).

The view of anticipatory trading of HFT has the effect of liquidity and price efficiency due to the overreaction. HFT-got stocks that asset manager wants to buy cause the stock price to rise right before asset manager trading, thereby increasing their trading costs. Easley, Kiefer, O'Hara, and Paperman (1996) estimate the risk of information-based trading for a sample of New York Stock Exchange (NYSE. If the asset manager makes transactions to create a surge in liquidity, then HFT purchases reduce efficiency by utilizing temporary increases in share prices above their fundamental values (Baron, Brogaard, Hagströmer, \& Kirilenko, 2019). HFT can anticipate valuable information, and then their purchases increase stock prices to fundamental values faster than they should. These circumstances contributed to research examining how shifts in electronic markets and automated trading strategies affect liquidity and price efficiency (Hirschey, 2013). Research on the effects of automation by Breckenfelder (2013) shows that increased electronic order traffic on the NYSE is associated with lower bid-ask spreads and less price discovery through trading.

Hirschey (2013) and Biais (2013) explain that one aspect that causes the HFT effect on liquidity is by examining whether HFT liquidity enhances the strategies to anticipate and precede the flow of orders of traditional asset managers. HFT can anticipate mutual fund trading, for example, if the mutual fund divides a large order into a series of smaller orders (Easley et al., 1996), and their initial trade reveals information about their future trading intentions. If, indeed, HFT can estimate the traditional asset manager orders flow, then the HFT might have an incentive to trade in early a traditional asset manager to benefit from the subsequent price impact (Baron, Brogaard, \& Kirilenko, 2012).

This study addresses the relationship between some variables of trading mechanism and probability of price reversal: first, analyzing the effect of market variables and stock transaction activities such as returns, trading volume, transaction frequency, liquidity, and volatility on the probability of price reversal, second, understanding the pattern of over-reaction in high-frequency trading (HFT) due to the effect of microstructure noise and, third, following the patterns and characteristics of HFT activities on the Indonesia Stock Exchange. The study was conducted for all price fractions, which are divided into three, namely: low price (IDR 1-2), medium price (IDR 5-10), and high price (IDR 25).

\section{HYPOTHESES DEVELOPMENT}

\subsection{Stock returns and price reversals}

The dynamics of the price reversal pattern depends on how quickly market participants respond to the flow and content of information received by the market to stock prices adjusted to the latest content that affects return, in addition to dividend yields (Madhavan, 2000). Dyl (2019) and Biais (2013) state that to assess and measure the impact of various HFT behaviors on asset pricing and also compare and differentiate the contribution of their information to each other and all other market participants, they found how the discovery of prices among HFT actors varied by cross-section. The dynamics of stock price findings in HFT affect stock returns due to relatively large price 
shocks (shock prices) as a market response to incoming content, which ultimately results in price reversal or continuation (Litzenberger, Castura, \& Gorelick, 2012). When the new information arrives randomly into the market more frequently, then price shocks are more dynamic and increase the potential for overreaction so that the probability of price reversal will increase (Brogaard, Carrion, Moyaert, Riordan, Shkilko, \& Sokolov, 2018). Every overreaction will change the stock price (return) of the stock and cause a price reversal (Baron et al., 2019). As explained above, the reasonable hypothesis is as follows:

H1: Stock returns on HFT activities affect price reversals positively at the low price, medium price, and high price models (+).

\subsection{Trading volume and price reversal}

Overreaction behavior causes excess transaction activity, which triggers an increase in the trading volume of the equity (Baron et al., 2019). Dyl et al. (2019) conclude the overreaction is caused by an increase in market overload response to the arrival of news/information that triggers an increase in trading volume due to overreaction followed by price correction will form a consistent trading pattern. The fad trading activities also triggered the increased trading volume, namely the action of buying and selling securities (equity) that are not based on facts and the content of accurate information about the value of assets of the object of the transaction or not information-based decision (Benos \& Sagade, 2016). Thus, the fad trading factor can trigger excessive stock trading volume both in responding to good or bad information (Wong, Tan, \& Tian, 2009). In general, fad trading is caused by uninformed traders who do not know the fair value of the shares traded. The proportion of uninformed traders in the market determines the intensity of fad trading, so the more dominant fad trading causes the trading volume to be higher so that the probability of price reversal also increases (Hendershott \& Menkveld, 2014). Based on the described above, the hypothesis is as follows:

H2: $\quad$ Trading volume on HFT activities affect price reversals positively at the low price, medium price, and high price models (+).

\subsection{Frequency of transactions and price reversals}

Santosa and Hosen (2011) argue that the existence of the fad component will affect the stock price, which tends to be reversed due to fads dissipate, which results in mispricing. So there is a strong correlation between fad trading, transaction frequency, liquidity, and the probability of price reversal through the process of overreaction and price correction (Menkveld, 2016). Thus, the recent scientific literature describes an understanding that price reversal is caused by asymmetric information between traders to create trading noise that causes the frequency of stock transactions to increase and encourage stock prices to overreact (Van Kervel \& Menkveld, 2019). Madhavan (2002) also explained that the increased potential for price reversals is due to the shorter transaction period and the inaccurate valuation of assets, especially from traders with limited budgets. Hasbrouck (2013) states that an increase in transaction frequency does indeed have a positive effect on equity prices, but because price manipulation disrupts through a transaction frequency inducement.

H3: Transaction frequency on HFT activities affects price reversals positively at a low price, medium price, and high price models (+).

\subsection{Volume/frequency of transactions and price reversals}

The increase in the trading volume does not significantly cause an increase in the frequency of transactions, and vice versa, because the correlation between trading volume does not positively correlate with the frequency of transactions (Conrad et al., 2015; Santosa, 2011). This research needs to test with a proxy representing HFT activities, namely trading volume/transaction frequency $(\mathrm{V} / \mathrm{F})$, so that measurement of liquidity control is more accurate and proportional (Hasbrouck, 2013). Theoretically, $\mathrm{V} / \mathrm{F}$ is more effective in influencing the probability of price reversal because it is a more proportional liquidity proxy (Conrad, 2014; O'Hara, 2005). Then the appropriate hypothesis is as follows:

H4: Proxy of volume/frequency of transactions on HFT activities affects price reversals positively at the low price, medium price, and high price models. 


\subsection{Volatility and price reversal}

The process of "price formation" after the previous price shock, price movements are influenced by the unexpected component of the order flow that causes price volatility before reaching its equilibrium point (Fassas \& Siriopoulos, 2019). Santosa and Hosen (2011) and Hasbrouck (2013) explained that the equity price formation is based on the substance of the information accompanied by fad trading activities. Dyl et al. (2019) explain that higher volatility occurs in less liquid stocks with lower institutional ownership so that the potential for reversal probability is higher than liquid stock. The relationship of volatility with price reversal is very dynamic and is a control variable of the effects of liquidity pressures (Wang \& Xu, 2015). In other words, the dynamics of stock price shocks often leads to price volatility and triggers price reversal (French, Schwert, \& Stambaugh, 1987; Hendershott \& Riordan, 2012). Thus the hypothesis related to volatility is as follows:

H5: Price volatility on HFT activities affects price reversals positively at a low price, medium price, and high price models (+).

\subsection{Liquidity and price reversal}

Santosa and Hosen (2011) explained that stocks of firms with smaller institutional ownership tend to be illiquid, compared to stocks of big companies controlled by institutional (ultimate) investors. Besides, more prominent companies with higher institutional ownership also attract more news coverage and more attention from analysts and financial media, and this encourages efficient diffusion of firm-specific news. Narayan and Zheng (2010), Zhang (2012) argue that liquid stocks, which have abnormally increased liquidity due to price shocks, tend to experience a higher probability of price reversal than liquid stocks. Rapid and spontaneous liquidity pressures in the intraday period make the probability of price reversal even more significant and repeatedly occur before prices get equilibrium (Cheng et al., 2017). Liquidity is the essential variable that causes price reversal and continuity of stock price dynamics in HFT after price shocks due to the inclusion of dramat- ic-substantial information (Santosa \& Santoso, 2019; So \& Wang, 2014). The hypothesis that more liquid of stocks and news coverage negatively affect price reversal and continuation, where the pressure of price reversal and price continuity becomes bigger in smaller stocks and corporations with lower institutional ownership. The hypothesis that is under the elaboration of liquidity is as follows:

H6: Stock liquidity on HFT activities affects price reversals negatively/positively at a low price, medium price, and high price models (+/-).

The research framework is structured for the design of the analysis by correlating all independent variables with price reversal. Thus, the process of developing a hypothesis can be done better and in more detail. The independent variables (explanatory) used in general can be accepted as microstructure variables in HFT activities. The formulation of the framework is based on preliminary descriptions and previous literature studies summarized in related to HFT activities and price reversals (Dyl et al., 2019; Benosa \& Sagadeb, 2016; Hirschey, 2013; Cheng et al., 2017; Santosa, 2011), Santosa and Hosen (2011) and Easley \& O'Hara, 2005). The independent variables used in the design of the analysis include trading volume, frequency, volume per frequency (V/F), and high-frequency data-based volatility.

The research model equation based on the research framework as a whole is designed in the model of low price, medium price, and high price with logistic regression analysis as follows:

$$
\begin{aligned}
& \log \left[\frac{\hat{P}_{i, t}}{1-\hat{P}_{i, t}}\right]=\alpha_{0}+\alpha_{1} R_{i, t}+ \\
& +\alpha_{2} \text { Vol }_{i, t}+\alpha_{3} \text { Freq }_{i, t}+\alpha_{4}(\text { Vol/Freq })_{i, t}+ \\
& +\alpha_{5} \text { Volat }_{i, t}+\alpha_{6} \text { Liq }_{i, t}+u_{i, t}
\end{aligned}
$$

where $R_{i, t}$ is stock's return $i$ at period $t, V_{o l} l_{i, t}$ is trading volume stock $i$ at period $t$, Freq ${ }_{i, t}$ is frequency of transaction stock $i$ at period $t$, $(\mathrm{Vol} / \text { Freq })_{i, t}$ is ratio of volume to frequency transaction stock $i$ at period $t$, Volat $t_{i, t}$ is volatility stock $i$ at period $t, L i q_{i, t}$ is liquidity stock $i$ at period $t$. 


\section{METHOD AND DATA}

\subsection{Population and sampling}

The research method divides the stock price population into three sample groups: (i) low price with fractions IDR 1 and 2, (ii) medium price with fractions IDR 5 and 10; and (iii) high price with a fraction IDR 25. A purposive random sampling method was used with criteria, including (a) liquidity, (b) volatility, (c) active-liquid stock for more than five years, (d) market capitalization, (e) fundamental reputation, (f) leaders in the sector, and (g) ownership characteristics.

High-frequency data (HFD) were captured directly from the Indonesia Stock Exchange active running trade transactions. In particular, the price reversal dependent variable is categorical data 1 or 0 in the form of charts of price movements and independent variables, namely return, volume, frequency, volume/frequency, volatility, and liquidity. Direct capturing of running trades during $15 \mathrm{~min}$ -

Table 1. Tick size and maximum change (IDR) utes is required during the trading activity process. Then, the primary archival real-time transaction data are tabulated according to the stock price fraction classification. The HFD duration of the study was conducted in May-September 2019. Thus, the primary data obtained can be processed (run) with the help of statistical software such as EViews 10 and SPSS 21.

Three groups of share prices that have been in effect at the Indonesia Stock Exchange since 2016 include the low price group, medium price, and high price consisting of 5 (five) fractions (tick size), namely IDR 1-2, 5-10, and 25. Furthermore, maximum price changes are changes that are considered reasonable and rational during intraday trading takes place. Table 1 shows the details.

The results of the sampling following the established research criteria for low, medium, and high price stocks are shown in Table 2, where each price group consists of five stocks as a sample. Thus the total sample size is 15 stocks.

\begin{tabular}{lc|c|c|c}
\hline \multicolumn{1}{c}{ Price group } & Price range & Tick size & Max change \\
\hline Low & $<200$ & 1 & 2 \\
\hline Low & $200<500$ & 5 & 10 \\
Medium & $500<2000$ & 20 & 10 \\
\hline Medium & $2000<5000$ & 25 & 100 \\
\hline High & $\geq 5000$ & 250 \\
\hline
\end{tabular}

Table 2. Research samples

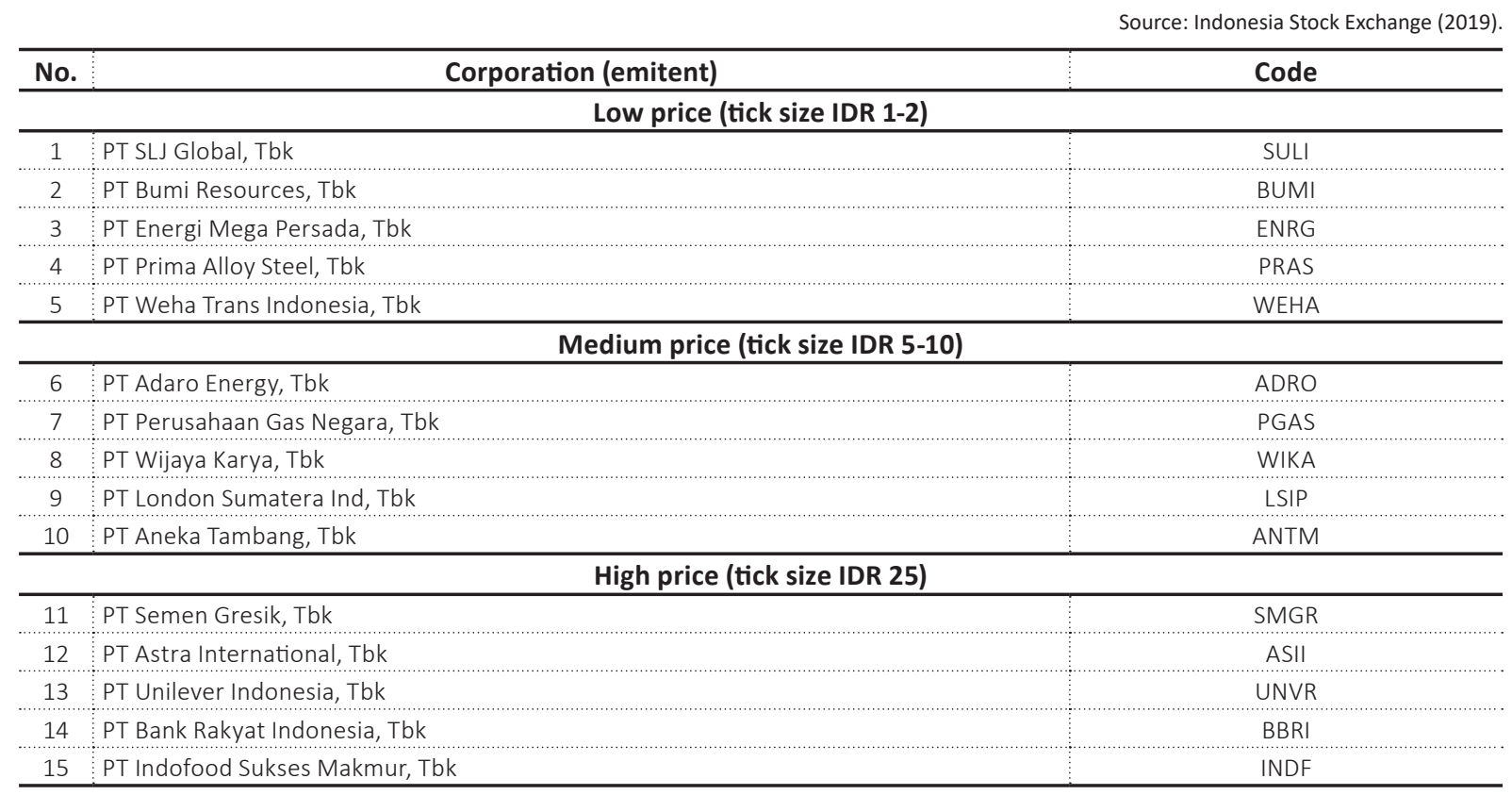


Table 2 shows fifteen research samples selected based on purposive sampling with the criteria of liquidity, volatility, transaction volume, market capitalization, financial performance, management credibility, and recorded for more than five years. Fifteen samples were considered to be representations of the low, medium, and high price (tick size) trading activities.

\subsection{Variable description and measurement}

The operationalization of the research variables, which are the objects of this research article is summarized systematically according to the logit regression equation in the design analysis. The research variables can be seen in Table 3 .

Table 3. Variable description and measurement

\section{ANALYSIS AND RESULTS}

\subsection{Descriptive analysis}

The results obtained around 13,257 primary HFT data observations per group of stock prices summarized in Table 4 show that the price reversal is getting lower with increasing stock prices. This fact indicates that stocks with the small tick size tend to experience reversals and vice versa for higher shares; the price has a stronger continuation pattern. Stock returns are higher at low price shares than medium or high price shares, thus, push for reversal is stronger in low price shares.

This table reports the descriptive analysis of five samples stock price category that is using HFD

\begin{tabular}{|c|c|c|}
\hline Variable & Indicator & Measurement \\
\hline Stock return & $\begin{array}{l}\text { Changes in the share price } \\
\text { divided by price } t-1\end{array}$ & $R_{t}=\ln \left(\frac{P_{t}}{P_{t-1}}\right)$, continue \\
\hline Trading volume & Number of shares (lots) traded & Measurements are carried out directly in real time during 15 minutes \\
\hline Frequency of transaction & Number of share transactions & Measurements are carried out directly in real time during 15 minutes \\
\hline $\mathrm{V} / \mathrm{F}$ & $\begin{array}{l}\text { Trading volume divided } \\
\text { by frequency }\end{array}$ & Ratio volume to frequency during 15 minutes \\
\hline Price volatility & Standard deviation of share price & $\sigma=\frac{s}{\sqrt{\tau}}, \sigma_{i, t}=\sqrt{\frac{1}{n} \sum_{i=1}^{n}\left(P_{i}-\bar{P}\right)^{2}}$ \\
\hline Liquidity & Turnover rate of shares traded & Turnover $=\frac{S T_{t-3}+S T_{t-2}+S T_{t-3}}{\text { Shares outstanding }}, S T:$ shares traded \\
\hline
\end{tabular}

Table 4. Descriptive analysis

\begin{tabular}{|c|c|c|c|c|c|c|c|}
\hline Descriptive statistic & Reversal & Return & Volume & Frequency & Vol/freq & Volatility & Liquidity \\
\hline \multicolumn{8}{|c|}{ Low price } \\
\hline Mean & 0.386432 & 0.00275 & 2466.580 & 22.68726 & 76.8844 & 95.78655 & 27.56126 \\
\hline Median & 0 & 0 & 54.50000 & 4.6377 & 20.8 & 16.15455 & 18.67595 \\
\hline Maximum & 1 & 0.646627 & 255270.0 & 750.0000 & 3000 & 26.32501 & 375.3615 \\
\hline Minimum & 0 & -0.446287 & 0.000000 & 0.000000 & 0 & 0.000000 & 0.000000 \\
\hline Std. dev. & 0.349401 & 0.034597 & 1605.76 & 34.72416 & 33.4064 & 46.71123 & 42.61660 \\
\hline \multicolumn{8}{|c|}{ Medium price } \\
\hline Mean & 0.3122 & 0.001696 & 7236.671 & 29.47712 & 82.89556 & 83.8894 & 42.07729 \\
\hline Median & 0 & 0 & 108.5000 & 18.264 & 32.1256 & 120.983 & 24.67595 \\
\hline Maximum & 1 & 0.369575 & 16695.00 & 454.0000 & 11600.5 & 391.261 & 375.3615 \\
\hline Minimum & 0 & -0.165985 & 0.000000 & 0.000000 & 0 & 21.1228 & 0.000000 \\
\hline Std. dev. & 0.3673 & 0.18277 & 2475.960 & 22.06340 & 46.5865 & 83.6693 & 52.61660 \\
\hline \multicolumn{8}{|c|}{ High price } \\
\hline Mean & 0.2322 & 0.000934 & 1723.671 & 18.4492 & 88.89556 & 59.8839 & 45.07429 \\
\hline Median & 0 & 0 & 332.5000 & 7.5528 & 34.9025 & 96.983 & 26.67588 \\
\hline Maximum & 1 & 0.889575 & 26695.00 & 454.0000 & 17600.5 & 201.261 & 392.3615 \\
\hline Minimum & 0 & -0.165985 & 0.000000 & 0.000000 & 0 & 12.2122 & 0.000000 \\
\hline Std. dev. & 0.3831 & 0.15972 & 2475.960 & 18.06340 & 32.5865 & 55.6363 & 55.90660 \\
\hline Observations & 13,257 & 13,257 & 13,257 & 13,257 & 13,257 & 13,257 & 13,257 \\
\hline
\end{tabular}


during the April 2019-August 2019 period on low, medium, and high pricing group.

The results of the descriptive analysis show that the trading of these stocks tends to be low on average, but with a high enough transaction frequency. These results indicate that stock transactions are carried out by traders with a relatively limited transaction budget so that the price movement is only around the bid-ask spread. This condition makes price movements more efficient because the price fraction is proportional to the value of the transaction.

\subsection{Heteroscedasticity test}

White heteroskedasticity test on samples of low price, medium price, and high price models produces the following (see Table 5).

Table 5. White heteroskedasticity test

\begin{tabular}{|c|c|c|c|}
\hline \multicolumn{4}{|c|}{$\begin{array}{l}\text { Test criteria: reject } \mathrm{HO} \text { if the probability value }<5 \% \text { and do not } \\
\text { reject otherwise. Based on the result of white heteroskedasticity } \\
\text { test above, it can be known that probability value (Obs*R- } \\
\text { squared) has value } 0.0000<0.05 \text {, so } \mathrm{HO} \text { is rejected, in other } \\
\text { words, there is heteroskedasticity high tick size data. This test } \\
\text { results explain to us that low price, medium price, and high } \\
\text { tick size are must be given 'special treatment' (such as white } \\
\text { heteroskedasticity) in order to influence its heteroskedasticity } \\
\text { can be eliminated. }\end{array}$} \\
\hline \multicolumn{4}{|c|}{ White heteroskedasticity test } \\
\hline \multicolumn{4}{|c|}{ Low price } \\
\hline F-statistic & 48.80758 & Probability & 0.000000 \\
\hline $\begin{array}{l}\text { Obs* } R- \\
\text { squared }\end{array}$ & 315.3651 & Probability & 0.000000 \\
\hline \multicolumn{4}{|c|}{ Medium price } \\
\hline F-statistic & 37.51850 & Probability & 0.000000 \\
\hline $\begin{array}{l}\text { Obs* } R- \\
\text { squared }\end{array}$ & 279.7140 & Probability & 0.000000 \\
\hline \multicolumn{4}{|c|}{ High price } \\
\hline F-statistic & 37.51850 & Probability & 0.000000 \\
\hline $\begin{array}{l}\text { Obs* } R- \\
\text { squared }\end{array}$ & 279.7140 & Probability & 0.000000 \\
\hline
\end{tabular}

Note: Significant level $\alpha=5 \%$.

Heteroscedasticity is found in all research variables used in low price, medium price, and high price models. Research variables that contain heteroscedasticity should receive special treatment so as not to affect the results of logistic regression. This particular action is needed so that the negative effects of heteroscedasticity can be eliminated.

\subsection{White heteroscedasticity regression}

Table 6 shows the findings of the regression model of white logistic as the treatment of heteroskedasticity problems of the following equation of price reversal (in logit):

$$
\begin{aligned}
& \log \left[\frac{\hat{P}_{i, t}}{1-\hat{P}_{i, t}}\right]=\alpha_{0}+\alpha_{1} R_{i, t}+\alpha_{2} \text { Vol }_{i, t}+ \\
& \alpha_{3} \text { Freq }_{i, t}+\alpha_{4}\left(\text { Vol }_{\text {Freq }}\right)_{i, t}+\alpha_{5} \text { Volat }_{i, t}+ \\
& +\alpha_{6} \text { Liq }_{i, t}+u_{i, t},
\end{aligned}
$$

where $R_{i, t}$ is the stock return to stock $i$ in fraction period $t, \mathrm{Vol}_{i, t}$ is the volume of transaction (lot) in log natural of stock $i$ in fraction $t$, the Freq $_{i, t}$ is the log natural of transaction frequency of stock $i$ in fraction period $t$, the ratio $(\mathrm{Vol} / \mathrm{Freq})_{i t}$ is a proxy of volume-frequency ratio of high-frequency trading activity, Volat $_{i, t}$ is the standard deviation $(t-7)$ of stock's price $i$ in fraction period $t$, and $L i q_{i, t}$ is turnover rate $(t-3)$ liquidity of stock $i$ in fraction period $t$.

\subsection{Analysis of price reversal determinats}

The analysis has to solve multicollinearity problems in all logit regression equations, and it is necessary to use the stepwise regression method. Model fit was formed for the three analysis models, namely low price, medium price, and high price. The results of the stepwise analysis can be

\begin{tabular}{|c|c|c|c|c|c|c|}
\hline \multirow{2}{*}{ Variable } & \multicolumn{2}{|c|}{ Low price model } & \multicolumn{2}{|c|}{ Medium price model } & \multicolumn{2}{|c|}{ High price model } \\
\hline & Coefficient & prob & Coefficient & prob & Coefficient & prob \\
\hline C & -3.136297 & 0.0000 & -2.76823 & 0.0000 & -3.749721 & 0.0000 \\
\hline Return & 23.33442 & 0.8877 & 29.7494 & 0.0008 & 31.72627 & 0.0001 \\
\hline Trading vol & $7.78 \mathrm{E}-05$ & 0.0120 & $7.2 \mathrm{E}-05$ & 0.0000 & $3.67 E-05$ & 0.5836 \\
\hline Frequency & -4.038509 & 0.0000 & $-8.8 \mathrm{E}-05$ & 0.0033 & 6.732253 & 0.0000 \\
\hline Vol/freq. & 0.000893 & 0.0009 & 0.04523 & 0.0000 & 0.007938 & 0.0000 \\
\hline Volatility & 0.049018 & 0.0028 & 0.00375 & 0.2730 & -0.000206 & 0.0740 \\
\hline Liquidity & -0.073902 & 0.4198 & -0.00046 & 0.3778 & 0.002897 & 0.2575 \\
\hline
\end{tabular}
seen in Table 6.

Table 6. Logit white regression treatment 
Table 7. Determinants of price reversal

\begin{tabular}{|c|c|c|c|c|c|c|}
\hline \multirow{2}{*}{ Variable } & \multicolumn{2}{|c|}{ Model low price } & \multicolumn{2}{|c|}{ Model medium price } & \multicolumn{2}{|c|}{ Model high price } \\
\hline & Coefficient & Wald & Coefficient & Wald & Coefficient & Wald \\
\hline Constant & -2.872 & 234.726 & -2.889 & 179.698 & -3.972 & 342.985 \\
\hline Return & 27.869 & 9.342 & 30.579 & 14.363 & 35.238 & 16.337 \\
\hline Trading vol & 0.001 & 10.955 & 0.003 & 31.869 & - & - \\
\hline Frequency & 0.006 & 9.627 & 0.006 & 7.692 & 0.032 & 82.340 \\
\hline Vol/Freq. & 0.002 & 47.470 & 0.038 & 46.721 & 0.008 & 87.394 \\
\hline Volatility & 0.000 & 18.252 & -0.002 & 6.276 & - & - \\
\hline Liquidity & -0.002 & 7.637 & 0.001 & 8.487 & - & - \\
\hline
\end{tabular}

Table 7 presents the results of logistic regression with step wise model analysis of the following form where probability of price reversal (in logit) is estimated (normality test, white heteroscedasticity, multicolinearity treatment) (see equation (1)).

The step-wise analysis results show different results from the previous white heteroskedasticity, where all liquidity variables in all analysis models show that the results do not affect price reversal. Firstly, one gives more attention to the very crucial variable, liquidity. The regression (Table 7) results where the liquidity variables for the low price and medium price models show significant results in a probability price reversal. However, in the high price model, different results are found with the low price and medium price models, in which the liquidity variable does not significantly influence the probability of price reversal.

Other results for the low price model show that the return, trading volume, frequency, V/F, and volatility significantly affect the price reversal. The medium price model noted the results that the trading volume, frequency, V/F, volatility, and liquidity variables affect the price reversal significantly. Furthermore, in the high price model, the return, frequency, and V/F variables have a significant effect, but the other two variables, namely trading volume, volatility, and liquidity, do not affect the price reversal.

\section{DISCUSSION}

Stepwise/Wald regression analysis on the logit equation is conducted to produce a fit model while eliminating the presence of multicollinearity problem. The results of the analysis show a better finding that the six independent variables significantly influence the probability of price reversal. This finding supports the explanation of Santosa and Hosen (2011). For the medium price and high price models, there are one and two insignificant variables. These findings provide new insights that the stock with the lowest price is influenced by intraday trading mechanism variables with excellent price formation efficiency. Overall, these findings show an interesting pattern where the higher the stock price, the smaller the influence of the intraday variable (Amini, Gebka, Hudson, \& Keasey, 2013). Furhermore, Dyl et al. (2019) explain how to price reversal and continuation correlate with previous stock returns, excess trading volume, stock liquidity, and company-specific information.

The findings support that reversal tends to occur between liquid stocks with smaller market capitalization and lower institutional ownership. Stocks that are infrequent trading with small tick size tend to overreact when there is liquidity pressure and produce high volatility, thereby increasing the probability of price reversal (Guilbaud \& Pham, 2013). The results of the analysis show the consistency of the overreaction hypothesis where companies with high price shocks when information is received the market is more likely to experience price reversal (Dyl et al., 2019; Chung \& Chuwonganant, 2018).

The contribution of another finding is the use of volume/frequency and transaction frequency variables in the form of the price reversal probability model. The lowest price category has high liquidity risk due to inconsistent trading activities or only temporary trading (Santosa \& Hosen, 2011). So psychologically, the HFT tends to hold holding cash rather than holding stock because they are worried about inconsistent stock liquidity (Chen, 
2005). Besides, low-value stocks are underreported and less attractive to equity analysts. Another thing is the lack of institutional ownership in shares of this type. Then the effect of price shocks has a more significant impact on the probability of price reversal compared to blue chips (Berkman \& Comerton-Forde, 2011). Furthermore, cumulative abnormal returns and higher trading volumes are positively correlated with the probability of price reversal, especially the first one-day price shock (Dyl et al., 2019; Benosa \& Sagabed, 2016; Baron et al., 2012; Brogaard et al., 2012).

Hisrchey (2013) and Easley, Kiefer, O'Hara, and Paperman (1996b) explained that HFT, as a liquidity provider, can exert liquidity pressure when sluggish stock transactions without relevant information that trigger price volatility and the probability of price reversal. HFT applies this liquidity pressure in specific periods in intraday trading, generally forming certain specific patterns (Admati \& Pfleiderer, 1988; Conrad et al., 2015; Biais, Foucault, \& Moinas, 2012). This phenomenon provides benefits for patient traders who use limit orders more often than market orders that make instant transactions at a specific price. This discovery contributes to the relation- ship between trading limit strategies and market orders on stock price volatility and price reversals (Biais et al., 2012). The higher price reversal on small shares is also influenced by private information contained in insider trading activities that are positively correlated with overreaction. Inversely, price continuation weakens when the price shock tends to be extreme.

Hirschey (2013) explained where the HFT could anticipate trades fund managers (institutional investors), for example, fund managers who manage stocks at higher prices and are more liquid must split large orders into smaller serial orders, and core trades reveal information related to future fund manager intentions. With this situation, it is difficult for fund managers to make buy orders on stocks at low prices because the intentions are easily indicated by HFT who directly anticipate the flow of orders. Then, there is a surge in liquidity that triggers a price spike and increases the probability of price reversal (Santosa \& Hosen, 2011; Dyl et al., 2019). HFT can predict traditional asset manager order flow accurately in various ways, so HFT is more profitable than traditional asset managers because it could estimate prices (Korajczyk \& Murphy, 2015).

\section{CONCLUSION}

The discussion shows that the smaller the stock price (in the low price model), the more significant the effect of the independent variable on the probability of a price reversal, conversely, the higher the stock price (medium price and high price models) shows that the smaller the number of variables that have a significant effect. The liquidity factor showed that the lower the stock price, the smaller the liquidity, thus, creating a higher liquidity risk for investors, especially high-frequency traders (HFTs). Low price stocks also reduce the interest of institutional investors, and fund manager's specific information is rarely reported and analyzed. Low price stocks have high liquidity risk due to inconsistent trading activities or only temporary trading. Thus illiquid shares are preferred by retail investors who are generally HFTs (uninformed traders) so that the potential price reversal is higher compared to more expensive stocks.

HFT, which tends to trade low price shares, tends to hold holding cash rather than holding stock because they are worried about temporary liquidity of shares due to lack of reporting and low interest in equity analysts discussing it. This type of stock has more rumors than financial performance information. Then the price reversal probability is higher than the high price stocks (blue chips) because the effect of price shocks has a more significant impact so that there are cumulative abnormal returns and higher trading volume positively correlated with the probability of price reversal, the especially one-day price shock first. Fund managers (informed traders) tend to avoid low price stocks because their prices are more responsive in block trading. After all, trading values are limited, so trading tactics of large investors are complicated. Thus, these low price stocks make it difficult for asset managers because each of their transactions creates significant price volatility and HFTs easily detected (retail traders). 
The $\mathrm{V} / \mathrm{F}$ variable is the most potent variable to predict the probability of price reversal because this variable is a ratio that represents the two HFT variables on the Indonesia Stock Exchange. The V/F variable can explain the probability of price reversal when the stock price experiences a bounce effect around the bid-ask spread.

\section{LIMITATIONS AND AVENUE FOR FUTURE RESEARCH}

As mentioned previously, there are three limitations to this research. First, the use of analytical models should add overreaction variables such as market-adjusted returns, mean-adjusted trading volumes, and mediating variables. Second, using the event study method associated with substantially-dramatic events (news) that cause shock prices. Third, combining anticipatory models, in this case, the competition between HFTs and asset managers/institutional investors in predicting order flow and price movements.

\section{ACKNOWLEDGMENT}

Many thanks to Armida S. Alisjahbana, Roy H. Sembel, Budiono, Rahardi S. Rahmanto, and the anonymous referee/reviewer for valuable inputs and feedback.

\section{REFERENCES}

1. Amini, S., Gebka, B., Hudson, R., \& Keasey, K. (2013). A review of the international literature on the short term predictability of stock prices conditional on large prior price changes: Microstructure, behavioral and risk related explanations. International Review of Financial Analysis, 26, 1-17. https://doi. org/10.1016/j.irfa.2012.04.002

2. Angel, J. J., \& McCabe, D. (2013). Fairness in Financial Markets: The Case of High Frequency Trading. Journal of Business Ethics, 112, 585595. https://doi.org/10.1007/s10551 012-1559-0

3. Baron, M., Brogaard, J., \& Kirilenko, A. A. (2012). The Trading Profits of High Frequency Traders. SSRN Electronic Journal. https://doi. org/10.2139/ssrn.2106158

4. Baron, M., Brogaard, J., Hagströmer, B., \& Kirilenko, A. (2019). Risk and return in high-frequency trading. Journal of Financial and Quantitative Analysis, 54(3), 9931024. https://doi.org/10.1017/ S0022109018001096

5. Benos, E., \& Sagade, S. (2012). High-Frequency Trading Behaviour and Its Impact on Market Quality: Evidence from the UK Equity Market. SSRN Electronic
Journal. Retrieved from https:// www.researchgate.net/publication/256041049_High-Frequency_ Trading_Behaviour_and_Its_Impact_on_Market_Quality_Evidence_ from_the_UK_Equity_Market

6. Benos, E., \& Sagade, S. (2016). Price discovery and the crosssection of high-frequency trading. Journal of Financial Markets, 30, 54-77. https://doi.org/10.1016/j. finmar.2016.03.004

7. Berkman, H., \& Comerton-Forde, C. (2011). Market microstructure: A review from down under. Accounting and Finance, 51(1), 5078. https://doi.org/10.1111/j.1467629X.2010.00377.x

8. Biais, B., Foucault, T., \& Moinas, S. (2012). Equilibrium HighFrequency Trading. SSRN Electronic Journal. https://doi.org/10.2139/ ssrn. 2024360

9. Biais, B., Foucault, T., \& Moinas, S. (2015). Equilibrium fast trading. Journal of Financial Economics, 116(2), 292-313. https://doi. org/10.1016/j.jfineco.2015.03.004

10. Bloomfield, R., O'Hara, M., \& Saar, G. (2009). How noise trading affects markets: An experimental analysis. Review of Financial Studies. Retrieved from https://papers.ssrn. com/sol3/papers.cfm?abstract_ id $=994379$

11. Breckenfelder, J. H. (2013). Competition between HighFrequency Traders and Market Quality. SSRN Electronic Journal. https://doi.org/10.2139/ ssrn.2264858

12. Brogaard, J., Carrion, A., Moyaert, T., Riordan, R., Shkilko, A., \& Sokolov, K. (2018). High frequency trading and extreme price movements. Journal of Financial Economics, 128(2), 253-265. https://doi.org/10.1016/j.jfineco.2018.02.002

13. Cheng, S., Hameed, A., Subrahmanyam, A., \& Titman, S. (2014). Short-Term Reversals and the Efficiency of Liquidity Provision. SSRN Electronic Journal. https://doi. org/10.2139/ssrn.2389408

14. Cheng, S., Hameed, A., Subrahmanyam, A., \& Titman, S. (2017). Short-term reversals: The effects of past returns and institutional exits. Journal of Financial and Quantitative Analysis. https://doi.org/10.1017/ S0022109016000958

15. Chordia, T., Roll, R., \& Subrahmanyam, A. (2011). Recent trends in trading activity and 
market quality. Journal of Financial Economics, 101(2), 243-263. https://doi.org/10.1016/j.jfineco.2011.03.008

16. Choudhry, T., \& Wu, Y. (2015). Momentum phenomenon in the Chinese Class A and B share markets. Review of Behavioral Finance. https://doi.org/10.1108/ RBF-06-2014-0032

17. Chung, K. H., \& Chuwonganant, C. (2018). Market volatility and stock returns: The role of liquidity providers. Journal of Financial Markets, 37, 17-34. https://doi. org/10.1016/j.finmar.2017.07.002

18. Conrad, J., Wahal, S., \& Xiang, J. (2015). High-frequency quoting, trading, and the efficiency of prices. Journal of Financial Economics, 116(2), 271-291. https://doi. org/10.1016/j.jfineco.2015.02.008

19. Dyl, E. A., Yuksel, H. Z., \& Zaynutdinova, G. R. (2019). Price reversals and price continuations following large price movements. Journal of Business Research, 95, 1-12. https://doi.org/10.1016/j. jbusres.2018.08.036

20. 20. Easley, D., Kiefer, N. M., O'Hara, M., \& Paperman, J. B. (1996). Liquidity, information, and infrequently traded stocks. Journal of Finance, 51(4), 1405-1436. https:// doi.org/10.1111/j.1540-6261.1996. tb04074.x

21. Fassas, A. P., \& Siriopoulos, C. (2019). Intraday price discovery and volatility spillovers in an emerging market. International Review of Economics and Finance, 59, 333 346. https://doi.org/10.1016/j. iref.2018.09.008

22. French, K. R., Schwert, G. W., \& Stambaugh, R. F. (1987). Expected stock returns and volatility. Journal of Financial Economics, 19(1), 3-29. https://doi.org/10.1016/0304405X(87)90026-2

23. Guilbaud, F., \& Pham, H. (2013). Optimal high-frequency trading with limit and market orders. Quantitative Finance, 13(1), 79-94. https://doi.org/10.1080/14697688.2 012.708779

24. Hendershott, T., \& Menkveld, A. J. (2014). Price pressures. Journal of Financial Economics, 114(3), 405-423. https://doi.org/10.1016/j. jifineco.2014.08.001
25. Hendershott, T., \& Riordan, R. (2012). High Frequency Trading and Price Discovery. SSRN Electronic Journal. https://doi. org/10.2139/ssrn.1928510

26. Hirschey, N. (2013). Do HighFrequency Traders Anticipate Buying and Selling Pressure? SSRN Electronic Journal. https://doi. org/10.2139/ssrn.2238516

27. Korajczyk, R. A., \& Murphy, D. (2015). High Frequency Market Making to Large Institutional Trades. SSRN Electronic Journal, 847. https://doi.org/10.2139/ ssrn. 2567016

28. Kudryavtsev, A. (2019). The effect of trading volumes on stock returns following large price moves. Economic Annals, 64(220), 85-116. https://doi.org/10.2298/ EKA1920085K

29. Litzenberger, R., Castura, J., \& Gorelick, R. (2012). The Impacts of Automation and High Frequency Trading on Market Quality. Annual Review of Financial Economics, 4, 59-98. https://doi.org/10.1146/ annurev-financial-110311-101744

30. Madhavan, A. (2000). Market microstructure: A survey. Journal of Financial Markets, 3(3), 205-258 https://doi.org/10.1016/S13864181(00)00007-0

31. Madhavan, A. (2002). Market Microstructure: A Practitioner's Guide. Financial Analysts Journal, 58(5), 28-42. https://doi. org/10.2469/faj.v58.n5.2466

32. Menkveld, A. J. (2016). The Economics of High-Frequency Trading: Taking Stock. Annual Review of Financial Economics, 8, 1-24. https://doi.org/10.1146/ annurev-financial-121415-033010

33. Narayan, P. K., \& Zheng, X. (2010). Market liquidity risk factor and financial market anomalies: Evidence from the Chinese stock market. Pacific-Basin Finance Journal, 18(5), 509-520. https://doi. org/10.1016/j.pacfin.2010.07.002

34. Santosa, P. W., \& Santoso, P. W. (2019). Does Exchange Rate Volatility cause Overreaction in the Capital Market? Evidence from Indonesia. International Journal of Finance and Accounting, 8(3), 80- 87. Retrieved from https://www.researchgate.net/
publication/337567862_Does_Exchange_Rate_Volatility_cause_ Overreaction_in_the_Capital_Market_Evidence_from_Indonesia

35. Santosa, P. W., \& Hosen, M. N. (2011). Probability of price reversal and intraday trading activity for low banking sector at Indonesia stock exchange. International Research Journal of Finance and Economics, 79. Retrieved from https:// www.academia.edu/35865278/ Probability_of_Price_Reversal_and_Intraday_Trading_Activity_ For_Low_Banking_Sector_at_Indonesia_Stock_Exchange

36. Savor, P. G. (2012). Stock returns after major price shocks: The impact of information. Journal of Financial Economics, 106(3), 635-659. https://doi.org/10.1016/j. jfineco.2012.06.011

37. So, E. C., \& Wang, S. (2014). News-driven return reversals: Liquidity provision ahead of earnings announcements. Journal of Financial Economics, 114(1), 20-35. https://doi.org/10.1016/j. jfineco.2014.06.009

38. Tetlock, P. C. (2011). All the news that's fit to reprint: Do investors react to stale information? Review of Financial Studies, 24(5), 1481-1512. https://doi.org/10.1093/rfs/hhq141

39. Van Kervel, V., \& Menkveld, A. J. (2019). High-Frequency Trading around Large Institutional Orders. Journal of Finance, 74(3), 1091-1137. https://doi.org/10.1111/jofi.12759

40. Wong, W. K., Tan, D., \& Tian, Y. (2009). Informed trading and liquidity in the Shanghai Stock Exchange. International Review of Financial Analysis, 18(1-2), 66-73. https://doi.org/10.1016/j. irfa.2008.11.002

41. Wu, Y., \& Choudhry, T. (2018). Information Uncertainty and Momentum Phenomenon Amidst Market Swings: Evidence From the Chinese Class A Share Market. Asia-Pacific Financial Markets, 25, 111-136. https://doi.org/10.1007/ s10690-018-9241-x

42. Zhang, F. (2012). High-Frequency Trading, Stock Volatility, and Price Discovery. SSRN Electronic Journal. https://doi.org/10.2139/ ssrn. 1691679 